\title{
Estudos de caso à luz da perspectiva freiriana: aprendizagens para a docência
}

\section{Case studies from the Freirian perspective: learning for teaching}

\author{
Ana Maria do Carmo ${ }^{1}$ \\ Andréia Francisco Afonso ${ }^{2}$
}

\begin{abstract}
Resumo
A docência é composta por múltiplos saberes construídos pelo professor durante o processo de formação inicial e durante o exercício da profissão. Há ainda aqueles que são elaborados a partir das vivências na educação básica, quando o docente ainda era estudante. Em relação ao processo formativo inicial, o subprojeto Química do Programa Institucional de Bolsa de Iniciação à Docência da Universidade Federal de Juiz de Fora tem proporcionado aos bolsistas de iniciação à docência, aprendizagens durante suas vivências no cotidiano escolar. Entre essas aprendizagens, destacamos a elaboração e aplicação de estudos de casos sobre o tema Alimentação, cujo objetivo foi envolver os futuros docentes na prática de sala de aula para que pudessem articular com autonomia o desenvolvimento de todas as etapas do trabalho. Vale destacar que foi um desafio para muitos deles, já que o curso de Química não tem uma disciplina voltada ao estudo do corpo humano. Entretanto, notamos que os futuros professores puderam desenvolver a autonomia, o senso crítico, a pesquisa e a argumentação junto aos estudantes, seguindo os princípios de Paulo Freire para uma educação democrática, emancipatória e libertadora. Diante das aprendizagens, percebemos que houve mudanças na postura dos bolsistas relacionadas a percepção da escola, enquanto ambiente de formação, e também em relação à carreira do magistério, que passou a ser vista com responsabilidade, dedicação e comprometimento.
\end{abstract}

Palavras-chave: Pibid. Paulo Freire. Estudos de caso. Educação em Ciências.

\begin{abstract}
Teaching is composed of multiple knowledge constructed by the teacher during the initial training process and during the exercise of the profession. There are also those that are elaborated from experiences in basic education, when the teacher was still a student. In relation the initial training process, the Chemistry subproject of the Institutional Program for Teaching Initiation Scholarship at the Federal University of Juiz de Fora has provided

\footnotetext{
${ }^{1}$ Doutoranda do PPGQ da UFJF. Mestre em Ciências da Saúde UFJF. Especialista em Biotecnologia UFLA. Graduada em Ciências Biológicas UFJF. Graduada em Química UNIFRAN. Professora da Secretaria de Educação de Juiz de Fora. E-mail: anadcarmo@yahoo.com.br

${ }^{2}$ Professora Adjunta do Departamento de Química da Universidade Federal de Juiz de Fora (UFJF). Doutora em Ciências (Universidade Federal de São Carlos - UFSCar). E-mail: andreia.afonso@ice.ufjf.br
} 


\section{-Revista de Iniciação à Docência, v.6, n.2, 2021- \\ Publicação: dezembro, 2021 - ISSN 2525-4332}

teaching initiation scholarship holders with learning during their experiences in daily school. Among these learnings, we highlight the development and application of case studies on the topic of Food, whose objective was to involve future teachers in the classroom practice so that they could autonomously articulate the development of all stages of the work. It is worth noting that it was a challenge for many of them, since the Chemistry course does not have a discipline focused on the study of the human body. However, we note that future teachers were able to develop autonomy, critical thinking, research and argumentation with students, following Paulo Freire's principles for a democratic, emancipatory and liberating education. In view of the learning experience, we noticed that there were changes in the position of the scholarship holders related to the perception of the school as a training environment, and also in relation to the teaching career, which came to be seen with responsibility, dedication and commitment.

Keywords: Pibid. Paulo Freire. Case studies. Science education.

\section{Introdução}

A docência é composta por múltiplos saberes. Alguns deles são construídos pelo professor durante o processo de formação inicial, outros durante o exercício da profissão. Há aqueles que são elaborados a partir das vivências na educação básica, quando o docente ainda era estudante. Sobre esses saberes, Tardif (2014, p. 11) afirma:

[...] não creio que se possa falar do saber sem relacioná-lo com os condicionantes e com o contexto do trabalho: o saber é sempre o saber de alguém que trabalha alguma coisa no intuito de realizar um objetivo qualquer. Além disso, [...] o saber dos professores é o saber deles e está relacionado com a pessoa e a identidade deles, com a sua experiência de vida e com a sua história profissional, com as suas relações com os alunos em sala de aula e com os outros atores escolares na escola, etc.

Logo, podemos afirmar que esses saberes são construídos por meio das interações com o outro e ao mobilizá-los, espera-se que o docente forme:

[...] o aluno no intuito de prepará-lo para viver na sociedade das mudanças e incertezas, e para ser capaz de enfrentar desafios. Além disso, ao professor é almejado que ele contribua para uma melhora qualitativa da sociedade, o que só se faz quando há o "compromisso político-social na docência" para a formação cidadã dos sujeitos (MENDES; BACCON, 2015, p. 39787).

No caso dos professores de Química, foco desse relato, as Diretrizes Curriculares Nacionais para os Cursos de Química, ao nortearem os currículos, vão nesse mesmo sentido, pois orientam para as ações que estejam voltadas à formação de um profissional que tenha as seguintes competências e habilidades:

- Ter consciência da importância social da profissão como possibilidade de desenvolvimento social e coletivo.

- Ter capacidade de disseminar e difundir e/ou utilizar o conhecimento relevante para a comunidade. [...]

- Conhecer criticamente os problemas educacionais brasileiros.

- Identificar no contexto da realidade escolar os fatores determinantes no processo educativo, tais como o contexto socioeconômico, política educacional, 


\section{-Revista de Iniciação à Docência, v.6, n.2, 2021- Publicação: dezembro, 2021 - ISSN 2525-4332}

administração escolar e fatores específicos do processo de ensinoaprendizagem de Química.

- Assumir conscientemente a tarefa educativa, cumprindo o papel social de preparar os alunos para o exercício consciente da cidadania. - Desempenhar outras atividades na sociedade, para cujo sucesso uma sólida formação universitária seja importante fator (BRASIL, 2001, p. 7).

Essa formação cidadã dos estudantes da Educação Básica, para que desempenhem suas funções em prol da sociedade, faz parte do trabalho docente e se dá a partir das relações sociais e culturais que se estabelecem nas escolas. Por meio delas, pode-se promover a reflexão e a criticidade na perspectiva de que todos têm "[...] condições de aprender e de criar, de arriscar-se, de perguntar, de crescer” (FREIRE, 1991, p. 42).

Na palavra "todos", citada anteriormente, estão incluídos professores e estudantes, uma vez que ambos são eternos aprendizes. Ao ensinar, as aprendizagens se dão a partir dos questionamentos dos estudantes, de suas dificuldades e das experiências que estes trazem para a sala de aula. Logo, o docente está em uma formação contínua, em "[...] um processo de desenvolvimento para a vida toda" (MIZUKAMI et al., 2006, p. 13).

Assim,

[...] ensinar e aprender se vão dando de tal maneira que quem ensina aprende, de um lado, porque reconhece um conhecimento antes aprendido e, de outro, porque, observado a maneira como a curiosidade do aluno aprendiz trabalha para apreender o ensinando-se, sem o que não o aprende, o ensinante se ajuda a descobrir incertezas, acertos, equívocos (FREIRE, 2001, p. 259).

Mas é importante que essa percepção aconteça ainda durante a formação inicial, especialmente, no momento em que os licenciandos têm a oportunidade de vivenciar práticas pedagógicas nas escolas, junto aos estudantes, seja no momento da escolha dos métodos e recursos didáticos mais adequados e/ou durante planejamento, e replanejamento de atividades e avaliações.

Nessa mesma direção, destacamos a importância da implementação de políticas públicas relacionadas a formação de professores, assim como o Pibid, que levem a aprendizagens de práticas docentes com todas as características já citadas, onde professores e estudantes estejam unidos em um processo educativo democrático e libertador.

Uma dessas políticas a ser tratada nesse relato é o Programa Institucional de Bolsas de Iniciação à Docência (Pibid), implementado pela Coordenação de Aperfeiçoamento de Pessoal de Nível Superior (Capes) em 2009, que será apresentado mais adiante.

Nesse contexto, do Pibid, realizamos um trabalho que teve como objetivo envolver bolsistas de iniciação à docência do Subprojeto Química, da Universidade Federal de Juiz de Fora (UFJF), na prática de sala de aula. Esse envolvimento foi 


\section{-Revista de Iniciação à Docência, v.6, n.2, 2021- \\ Publicação: dezembro, 2021 - ISSN 2525-4332}

promovido a partir do planejamento e aplicação de estudos de caso junto a estudantes do Ensino Fundamental, de modo que os futuros docentes pudessem desenvolver as ações com autonomia.

\section{O Programa Institucional de Bolsa de Iniciação à Docência: política pública voltada a formação de professores}

O Pibid é uma ação da Política Nacional de Formação de Professores do Ministério da Educação (MEC), que visa proporcionar aos licenciandos matriculados na primeira metade do curso, a aproximação e a imersão no cotidiano das escolas públicas de educação básica, conhecendo assim o contexto em que elas estão inseridas (BRASIL, 2020).

O Programa concede bolsas a esses licenciandos, que passam a atuar como bolsistas de iniciação à docência, para o desenvolvimento de diferentes ações com os seguintes objetivos:

\footnotetext{
- Incentivar a formação de docentes em nível superior para a educação básica;

- Contribuir para a valorização do magistério;

- Elevar a qualidade da formação inicial de professores nos cursos de licenciatura, promovendo a integração entre educação superior e educação básica;

- Inserir os licenciandos no cotidiano de escolas da rede pública de educação, proporcionando-lhes oportunidades de criação e participação em experiências metodológicas, tecnológicas e práticas docentes de caráter inovador e interdisciplinar que busquem a superação de problemas identificados no processo de ensino-aprendizagem;

- Incentivar escolas públicas de educação básica, mobilizando seus professores como conformadores dos futuros docentes e tornando-as protagonistas nos processos de formação inicial para o magistério; e

- Contribuir para a articulação entre teoria e prática necessárias à formação dos docentes, elevando a qualidade das ações acadêmicas nos cursos de licenciatura (BRASIL, 2020).
}

Para alcançá-los, devemos compreender o que coloca Freire (2001, p. 264): “[...] ensinar não pode ser um puro processo, como tanto tenho dito, de transferência de conhecimento do ensinante ao aprendiz. Transferência mecânica de que resulte a memorização maquinal [...]".

Desse modo, podemos afirmar que o Pibid busca superar o modelo de educação bancária (FREIRE, 2021), uma vez que;

Esse tipo de educação ainda é muito presente no Brasil, às vezes devido à formação precária do professor e outras porque o perfil da determinada escola segue esse parâmetro. De qualquer forma, é importante ressaltar que nem sempre é culpa do professor esse método bancário, algumas vezes isso é imperceptível por ele e outras é a forma que entidades superiores desejam que ele exerça sua função (SIQUEIRA; SANTOS, 2021, p. 9).

No Pibid ainda "[...] colocam-se lado a lado dois aspectos: o aluno, em processo de aprendizagem e participante do processo de formação e, também, o aluno como 
profissional em formação, que está aprendendo para aprender a ensinar e de que maneira ensinar" (FARIA; FARIA; SILVA, 2021, p. 867-868).

Por esses e outros motivos, Paniago e Sarmento (2017) apontam que o Pibid se apresenta como um espaço rico em possibilidades para a aprendizagem da docência e para a formação na e para a pesquisa. Os licenciandos podem, por meio da pesquisa, adentrar os diversos espaços da escola de educação básica, como, por exemplo, ocupar as bibliotecas; ter contato com as Tecnologias da Informação e Comunicação (TICS); vivenciar as relações multifacetadas, heterogêneas, afetivas e complexas de sala de aula e do entorno sociocultural da comunidade educativa; e realizar projetos de ensino e de intervenção com possibilidades de se transformarem em projetos de pesquisa.

Na Universidade Federal de Juiz de Fora (UFJF), um dos subprojetos que compõe o Pibid é o da Química, que iniciou as atividades em 2009 e tem sido um importante elo entre a Universidade e as escolas públicas de educação básica, de âmbito federal, estadual e municipal, localizadas na cidade de Juiz de Fora (MG).

Sant'Anna e Marques (2015) também reconhecem a importância dessa articulação entre a universidade e a escola básica no processo de formação dos futuros docentes. Para eles, essa articulação possibilita a construção de práticas educativas atualizadas e contextualizadas, pois envolvem todos os atores desse processo, assim como contribui para a gestão educacional nos seus diversos níveis.

Assim, a universidade, enquanto instituição formadora de profissionais da educação e produtora de conhecimento, pode contribuir de forma mais realista para a melhoria do ensino ao formar professores conectados com o cenário educacional no qual irão atuar e, ao mesmo tempo, produzir conhecimento que resulte em alternativas para os desafios encontrados pelas escolas do Brasil.

No ano de 2018 a 2020, com um novo formato proposto pela Capes, o subprojeto Química do Pibid da UFJF, passou por mudanças. O número de bolsistas de iniciação à docência (licenciandos em Química) passou para 24, havia três coordenadores de área (professores da UFJF) e uma supervisora (professora da educação básica) em cada uma das três escolas parceiras.

Assim, o subprojeto Química esteve presente em três escolas públicas de Juiz de Fora, sendo duas estaduais, atuando em turmas do Ensino Médio e da Educação de Jovens e Adultos (EJA); e uma escola municipal, atendendo alunos dos anos finais do Ensino Fundamental ( $6^{\circ}$ ao $9^{\circ}$ ano), e cada qual recebeu oito bolsistas de iniciação à docência.

Durante todo o período de atuação nestas escolas, os bolsistas desenvolveram e realizaram diversas atividades, buscando sempre novas alternativas para favorecer o aprendizado dos alunos com os quais interagiram. Para os futuros professores, a oportunidade de realizar atividades diretamente com alunos é extremamente 
importante, pois desenvolvem a capacidade de lidar com os alunos; adquirem segurança para planejar e ministrar uma aula; e aprendem a fazer na prática, testando e aplicando suas ideias.

Rostas (2019) reforça que o aprender é um ato de se apropriar de novos conhecimentos, de novas estratégias, de novos pensamentos e é essencial no exercício da docência. Entretanto, o professor precisa se sentir sujeito da sua aprendizagem e das suas múltiplas relações enunciativas, e sentir a escola como lugar de crescimento profissional permanente, já que "[...] não há docência sem discência, as duas se explicam e seus sujeitos, apesar das diferenças que os conotam, não se reduzem à condição de objeto, um do outro. Quem ensina aprende ao ensinar e quem aprende ensina ao aprender" (FREIRE, 1996, p.12).

Dentre as propostas realizadas no ano de 2019, os bolsistas que atuavam na escola municipal criaram e aplicaram estudos de caso como um recurso didático ${ }^{3}$ nas aulas de Ciências do Ensino Fundamental, procurando abordar temas do cotidiano recorrentes nas mídias. De acordo com Sá e Queiróz (2010), o estudo de caso tem o objetivo de inserir os educandos no centro do processo educativo, transformando-os em responsáveis pelo seu aprendizado, estimulando a capacidade e a habilidade de resolução de problemas e melhorias na expressão escrita e oral. Ainda possibilita o contato com fenômenos do cotidiano.

Neste relato, supervisora da escola e coordenadora da universidade, buscaram apresentar e discutir as contribuições na aprendizagem da docência de oito bolsistas do subprojeto Química da UFJF, ao planejarem e aplicarem oito estudos de caso em quatro turmas do Ensino Fundamental, em consonância com os ideais freirianos.

\section{O planejamento, a elaboração e a aplicação dos estudos de caso pelos pibidianos à luz da perspectiva freiriana}

Esses oitos bolsistas de iniciação à docência atuavam em uma escola municipal localizada na zona norte de Juiz de Fora, acompanhando as turmas de $8^{\circ}$ ano - A e B - e de $9^{\circ}$ ano - A e B -, totalizando cerca de 80 estudantes do Ensino Fundamental, com faixa etária variando dos 13 aos 15 anos, junto a professora supervisora.

A atividade proposta para as quatro turmas consistiu em estudos de caso, que foram considerados como recursos didáticos, conforme explicitado anteriormente. Eles foram escolhidos pelos bolsistas por possibilitar aos alunos do Ensino Fundamental serem protagonistas no processo de aprendizagem, participando, dessa forma, ativamente nas aulas, no sentido de que ensinar não é transferir conhecimento, mas sim criar possibilidades para a sua produção ou para a sua construção (FREIRE, 1996).

\footnotetext{
3 Existem diferentes compreensões para o estudo de caso. Nesse trabalho, ele foi empregado como um recurso didático, com base no livro de Sá e Queiroz (2009). Outros autores, como Gil (2009), o utilizam como tipologia de pesquisa e não como estratégia de ensino.
} 


\section{-Revista de Iniciação à Docência, v.6, n.2, 2021- \\ Publicação: dezembro, 2021 - ISSN 2525-4332}

Os estudos de caso foram planejados para serem desenvolvidos em três etapas, de acordo com a proposta pedagógica freiriana:

1) Investigação: corresponde à busca, no "universo" do educando e da sociedade em que ele vive, às palavras e temas centrais que estejam vinculados à sua vida, possibilitando a contextualização;

2) Tematização: corresponde à etapa em que alunos e professor trabalham os temas, procurando o seu significado social e

3) Problematização: nessa etapa, aluno e professor buscam enxergar além de uma primeira visão, elaborando uma visão crítica do mundo (JESUS; SILVA, 2017, p. 4643).

Para a criação dos estudos de caso, os bolsistas procuraram identificar os assuntos de interesse dos alunos e que são continuamente divulgados na mídia, muitas vezes, de forma equivocada, gerando falsos saberes que podem influenciar na vida dos mesmos. A definição do tema para a aplicação dos estudos de caso, de caráter investigativo e crítico, foi balizada por alguns princípios da pedagogia freiriana, como diálogo, participação, pesquisa, criticidade, amorosidade e respeito.

Para essa identificação, os futuros professores realizaram uma roda de conversa para que os estudantes pudessem manifestar quais temas gostariam de estudar de forma mais aprofundada nas aulas de Ciências, pois "[...] somente quem escuta paciente e criticamente o outro, fala com ele, mesmo que, em certas condições, precise falar a ele" (FREIRE, 1996, p. 43).

Diante das manifestações dos estudantes, os bolsistas de iniciação à docência criaram e organizaram estudos de caso sobre o tema Alimentação, envolvendo os seguintes pontos: lactose, diet e light, glúten, falsos alimentos saudáveis, alergias, dietas, colesterol e reaproveitamento de alimentos.

Por meio dos pontos citados também foi possível trabalhar conteúdos introdutórios de Bioquímica, abordando questões cotidianas, tornando os conceitos científicos menos abstratos (Quadro 1).

Quadro 1: Pontos e conteúdos científicos abordados em cada estudo de caso.

\begin{tabular}{|l|l|l|}
\hline Estudos de caso & Tema & Conteúdos abordados \\
\hline Estudo I & Lactose & $\begin{array}{l}\text { Bioquímica dos alimentos, } \\
\text { saúde }\end{array}$ \\
\hline Estudo II & Light e diet & Diabetes, pressão alta \\
\hline Estudo III & Glúten & $\begin{array}{l}\text { Emagrecimento, calorias dos } \\
\text { alimentos com glúten }\end{array}$ \\
\hline Estudo IV & Falsos saudáveis & $\begin{array}{l}\text { Mitos e verdades sobre } \\
\text { alimentos saudáveis }\end{array}$ \\
\hline Estudo V & Alergia alimentar & $\begin{array}{l}\text { Reação alérgica, perigo da } \\
\text { automedicação }\end{array}$ \\
\hline
\end{tabular}


-Revista de Iniciação à Docência, v.6, n.2, 2021-

Publicação: dezembro, 2021 - ISSN 2525-4332

Quadro 1: Pontos e conteúdos científicos abordados em cada estudo de caso. (continuação)

\begin{tabular}{|l|l|l|}
\hline Estudo VI & Dieta & $\begin{array}{l}\text { Dietas da moda, saúde e } \\
\text { qualidade de vida }\end{array}$ \\
\hline Estudo VII & Colesterol & $\begin{array}{l}\text { Gorduras trans, estilo de vida e } \\
\text { saúde }\end{array}$ \\
\hline Estudo VIII & Reaproveitamento de alimentos & Desperdício, valor nutricional \\
\hline
\end{tabular}

Fonte: Elaborado pelas autoras.

A escolha da temática Alimentação vai ao encontro das orientações da Base Nacional Comum Curricular (BNCC), que almeja o desenvolvimento integral dos estudantes por meio da aquisição de competências, nas diferentes áreas do conhecimento. Para a área de Ciências da Natureza e suas Tecnologias, consta que:

Para debater e tomar posição sobre alimentos, medicamentos, combustíveis, transportes, comunicações, contracepção, saneamento e manutenção da vida na Terra, entre muitos outros temas, são imprescindíveis tanto conhecimentos éticos, políticos e culturais quanto científicos. Isso por si só já justifica, na educação formal, a presença da área de Ciências da Natureza, e de seu compromisso com a formação integral dos alunos (BRASIL, 2017, p.321) (grifo nosso).

Portanto, a BNCC mostra a preocupação em capacitar o aluno da educação básica a enfrentar os desafios presentes em seu cotidiano. E ainda ressalta a importância de organizar as situações de aprendizagem partindo de questões que sejam desafiadoras e que estimulem o interesse e a curiosidade científica dos estudantes (BRASIL, 2017).

Durante o planejamento dos estudos de caso, os futuros professores esperavam que os estudantes das quatro turmas pudessem: comparar e diferenciar os alimentos de acordo com suas composições; reconhecer os malefícios e benefícios dos alimentos; mostrar a influência da sociedade nos padrões de consumo; relacionar o consumo e o reaproveitamento de alimentos, de modo a compreender como essa relação pode impactar na saúde e no meio ambiente. Assim, a aprendizagem estaria a favor da transformação da realidade, para nela intervir, sendo, portanto, um aprender para construir, reconstruir, constatar e mudar (FREIRE, 1996).

Todos os oito estudos de caso foram construídos pelos bolsistas de iniciação à docência, de forma colaborativa, com a supervisão e análise da professora regente das turmas, e supervisora do subprojeto Química, e de uma das coordenadoras de área, para os ajustes necessários, todos membros do subprojeto Química do Pibid da UFJF.

Os oito casos criados consistiam em histórias curtas em que as personagens apresentavam algum problema de saúde em decorrência da alimentação, divulgado pela mídia, como mostra o estudo de caso I que foi distribuído aos estudantes: 


\section{-Revista de Iniciação à Docência, v.6, n.2, 2021- \\ Publicação: dezembro, 2021 - ISSN 2525-4332 \\ Estudo de Caso I}

Luciene tem 40 anos, mora na cidade, e foi visitar alguns parentes no interior de Minas Gerais, que possuem uma fazenda produtora de queijo. Neste fim de semana, a mesa de café da manhã foi farta, com café, leite, queijo, pães, biscoitos, bolos e frutas.

Após voltar para a casa na segunda feira começou a se sentir mal, mas foi trabalhar assim mesmo, no trabalho conversou com sua colega Rose.

- Oi Rose, bom dia, tudo bem?

- Oi Lu, tudo bem e com você?

- Eu não estou muito bem não, estou com mal-estar.

- O que você está sentindo?

- Estou com mal-estar, parece que vou vomitar, estou com diarreia, dores na barriga e estou me sentindo inchada.

- Mas há quanto tempo você está sentindo isso?

- Sempre sinto isso quando chego da fazenda dos meus tios. Nas últimas três semanas, venho sentindo isso.

- Mas você está comendo alguma coisa diferente lá?

- Não, a mesma coisa que sempre comia: aquele cafezinho fresquinho, queijo fresco e aquele leite delicioso da roça.

- Mas foi depois do café que você passou mal?

- Sim!

- Tem uma prima minha que tem alergia a leite e tudo que vem dele. Vai ver você está com isso também.

- É, vou pedir ao meu filho para pesquisar para mim.

Você é este filho e ficou preocupado. Resolveu, então, pesquisar sobre os sintomas e a suspeita da colega, até descobrir o que ela tem, e como resolver.

Ps.:

$\rightarrow \quad$ Fazer um cartaz com as informações pesquisadas.

$\rightarrow \quad$ Colocar rótulos de alimentos com informações sobre a composição, que tenham relação com o estudo.

O estudo de caso I, assim como os demais, tiveram o intuito de possibilitar ao aluno momentos de reflexão e questionamentos sobre o que se lê, vê e escuta nos diversos meios de comunicação e, assim, possibilitar a avaliação de um posicionamento seguro e consciente, embasado no conhecimento científico, mas sem descartar os seus saberes. Freire (1996) afirma que a intervenção sobre a realidade é uma tarefa incomparavelmente complexa, mas geradora de novos saberes.

Esse recurso didático, ao tratar de um tema atual e conhecido, foi considerado pelos futuros professores de Química com algo que despertaria a curiosidade dos estudantes e, portanto, estimularia o seu envolvimento na investigação de uma solução para o problema em questão. 


\section{-Revista de Iniciação à Docência, v.6, n.2, 2021- \\ Publicação: dezembro, 2021 - ISSN 2525-4332}

Assim, os alunos foram organizados em grupos de até quatro integrantes, de maneira que cada equipe ficou responsável pela solução de um problema proposto. Portanto, eles deveriam identificar o que havia de errado a partir dos sintomas relatados nas histórias, para, depois, propor uma solução. Neste sentido, esse recurso foi planejado de forma a tornar o aluno um agente ativo na construção de seu aprendizado, valorizando suas experiências e incentivando-o a buscar novos saberes com autonomia, pesquisa, estudo e debates com seus pares e demais colegas de sua turma.

Para a resolução do problema, foi preciso empenho, pesquisa, estudo e discussões por parte dos discentes, que teve que ser apresentada com argumentos coerentes. Dessa forma, podemos afirmar que os bolsistas de iniciação à docência foram educadoreseducandos.

[...] os educadores-educandos têm práticas pautadas pela problematização e o conteúdo programado não se resume a uma imposição de informações preestabelecidas. Assim, temos que a educação verdadeira não acontece de uma pessoa a outra, mas de uma pessoa com a outra (WASUM; FRAGA; MAURENTE, 2021, p. 81).

Além disso, os futuros professores buscaram com a atividade: promover a autonomia dos estudantes, favorecer as discussões entre os grupos e proporcionar a oportunidade de expressão sobre o que sabiam (conhecimentos prévios) e sobre o que aprenderam. Portanto, “[...] ensinar não é transferir inteligência do objeto ao educando, mas instigálo no sentido de que, como sujeito cognoscente, se torne capaz de inteligir e comunicar o inteligido" (FREIRE, 1996, p.45).

Após os estudantes chegarem a uma resolução, os bolsistas de iniciação à docência ministraram uma aula utilizando slides, a fim de discutir os oito casos e o percurso até a solução delineada por cada grupo.

\section{Aprendizagens da docência dos bolsistas de iniciação à docência de Química}

Durante a apresentação da resolução dos casos, os bolsistas de iniciação à docência perceberam que os alunos se envolveram com a atividade proposta e se empenharam na busca da solução para o problema relatado em cada estudo. Além disso, muitos relataram que iriam adotar novos hábitos alimentares influenciados pelos novos saberes.

Em relação à lactose - estudo de caso I - os estudantes conseguiram distinguir alergia e intolerância a essa substância, e demonstraram ainda uma visão crítica a respeito do modismo das dietas com restrição a esse carboidrato. Um estudo realizado por Lee et al. (2021) mostrou que os livros didáticos analisados por eles "trazem os nutrientes necessários de maneira geral, abordam as doenças relacionadas à má alimentação, estimulam a análise dos hábitos alimentares pessoais” (p. 8).

Sendo assim, a associação destes livros com estratégias dinâmicas, construtivistas podem ser capazes de influenciar na educação alimentar dos 


\title{
-Revista de Iniciação à Docência, v.6, n.2, 2021- Publicação: dezembro, 2021 - ISSN 2525-4332
}

alunos. Permitindo que esses sejam capazes de analisarem seus hábitos alimentares, modificá-los e estimularem a mudança da sociedade (LEE et al., 2021, p. 8).

Ao apresentarem a resolução do estudo de caso II sobre alimentos diet e light, ficou claro que o grupo conseguiu compreender as características de cada um deles e ainda os associaram a doenças, como diabetes e hipertensão arterial, com estilo de vida e dieta alimentar.

\begin{abstract}
Embora a literatura da área e os documentos oficiais destinados à reforma da educação básica como as Diretrizes Curriculares Nacionais do Ensino Médio (DCNEM) e os Parâmetros Curriculares Nacionais para o Ensino Médio (PCNEM) já tenham apontado a importância de um ensino contextualizado, não só na educação básica, mas também nos cursos de formação de professores, ainda parece ser imperativa a discussão de abordagens contextualizadas nesses cursos, que possam minimizar também os problemas no processo de ensino e aprendizagem da educação básica (FERNANDES; MARQUES; DELIZOICOV, 2016, p. 11).
\end{abstract}

Portanto, os bolsistas de iniciação à docência indicaram que, mesmo que o curso de Licenciatura em Química ainda não tenha proporcionado abordagens contextualizadas, eles conseguiram trazer o cotidiano para a sala de aula, por meio do tema Alimentação, aproximando o conhecimento escolar da vida cotidiana dos estudantes.

Ao falarem das dietas com restrição de glúten - estudo de caso III -, os estudantes apresentaram argumentos convincentes para evidenciar que alguns alimentos que não apresentam esse nutriente são extremamente calóricos e não favorecem a perda de peso. E que dietas sem glúten são necessárias para pessoas com a doença celíaca, que são intolerantes a esta substância.

Acreditamos que a argumentação está diretamente relacionada ao pensamento crítico. Este último,

[...] apresenta duas dimensões: uma relacionada com a argumentação, ao uso e a busca de provas, e outra relacionada com a emancipação social, isto é, ao desenvolvimento da opinião independente e análise crítica dos discursos que justificam as desigualdades (SOUSA; GEHLEN, 2015, p. 2).

O desenvolvimento da opinião independente se dá por meio da autonomia. O desenvolvimento da autonomia nos educandos, pelos docentes, se dá na:

[...] convivência amorosa com seus alunos e na postura curiosa e aberta que assume e, ao mesmo tempo, provoca-os a se assumirem enquanto sujeitos sócios-históricos-culturais do ato de conhecer, é que ele pode falar do respeito à dignidade e autonomia do educando (FREIRE, 1996, p. 7).

Os discentes se mostraram surpresos com relação a alguns alimentos que julgavam serem saudáveis, durante a resolução do estudo de caso IV. Ao se apropriarem desse conhecimento, muitos relataram que iriam deixar de consumir alguns alimentos, como gelatina, cereal em barra, dentre outros que julgavam serem alimentos saudáveis. 


\section{-Revista de Iniciação à Docência, v.6, n.2, 2021- \\ Publicação: dezembro, 2021 - ISSN 2525-4332}

Interessante também foi a descobertas dos alunos sobre a alergia que alguns alimentos podem causar nas pessoas, que nesse estudo de caso $\mathrm{V}$ foram exploradas as alergias causadas por frutos do mar e amendoim. Eles puderam esclarecer os principais sintomas causados por alergias a alimentos e também como proceder nesses casos, além da conscientização de não se automedicarem.

No estudo de caso abordando dietas restritas a carboidratos ou a proteínas estudo de caso $\mathrm{VI}$-, os estudantes mostraram que essas dietas poderiam prejudicar a saúde e ainda, puderam questionar algumas delas que são encontradas na internet e, muitas vezes, tidas como milagrosas para a perda de peso, mas que são maléficas para a saúde das pessoas. Portanto, "há a necessidade de se superar a dicotomia entre o conhecimento técnico/conceitual e o cultural" (FERNANDES; MARQUES; DELIZOICOV, 2016, p. 19)

Outra questão abordada foi o consumo exagerado do óleo de coco, e para a surpresa dos alunos, suas pesquisas os fizeram descobrir que o consumo exagerado desse alimento pode ser prejudicial à saúde e favorecer o aumento do colesterol - estudo de caso VII. Provavelmente, se não tivessem participado da atividade, poderiam continuar acreditando nas notícias relacionadas ao óleo de coco e, quem sabe, fazendo uso contínuo em sua alimentação.

Segundo Lee et al. (2021, p. 1), “existem inúmeras doenças associadas a má alimentação e os índices são alarmantes, além da questão da obesidade que representa uma grande preocupação entre os adultos e cada vez mais é mais frequente em crianças". Daí a importância da abordagem desse tema na educação básica.

Paulo Freire traz um posicionamento para a pesquisa no âmbito educacional, mostrando a importância dessa ação, que deve ser estendida ao processo de formação inicial de professores: "Ensinar, aprender e pesquisar lidam com esses dois momentos do ciclo gnosiológico: o em que se ensina e se aprende o conhecimento já existente e o em que se trabalha a produção do conhecimento ainda não existente". A "do-discência" docência-discência - e a pesquisa, indicotomizáveis, são assim práticas requeridas por estes momentos do ciclo gnosiológico (FREIRE, 1996, p. 14).

Por fim, finalizando as apresentações, os alunos que ficaram com o estudo de caso VIII relataram alternativas para evitar o desperdício de alimentos e para o seu reaproveitamento:

Segundo a Organização das Nações Unidas para Alimentação e Agricultura (FAO) toneladas de alimentos são desperdiçadas anualmente, cerca de 1,3 bilhões de toneladas em todo o mundo, causando grandes perdas econômicas e também um impacto nos recursos naturais que são de extrema importância para a humanidade. A falta de conhecimento da população sobre as propriedades nutricionais dos alimentos é um dos fatores que levam ao desperdício (ESTEVE; COELHO, 2021, p. 324-325). 
As apresentações também possibilitaram aos bolsistas de iniciação à docência identificarem os pontos abordados a partir do tema Alimentação, que devem ser aprofundados em outras aulas de Ciências e Química, durante o processo de formação inicial ou continuada.

Após o término dessa atividade, os bolsistas de iniciação à docência constataram que a metodologia do estudo caso investigativo foi uma boa estratégia para o ensino e abordagens de diversos conteúdos de ciências nesta etapa de escolarização. Alvarenga et al. (2018) afirmam também que, quando utilizaram o estudo de caso com método investigativo, notaram que os alunos se sentiram instigados, movidos pela curiosidade de aprender os conceitos abordados, participar e solucionar os problemas que thes eram impostos.

Para essa solução, os futuros educadores perceberam que o conhecimento prévio dos estudantes foi importante para produzir e criar associações com as novas aprendizagens. Para Freire (2021, p.94),

\begin{abstract}
[...] a educação que se impõe aos que verdadeiramente se comprometem com a libertação não pode fundar-se numa compreensão dos homens como seres vazios a quem o mundo "encha" de conteúdos; não pode basear-se numa consciência especializada, mecanicistamente compartimentada, mas homens como "corpos conscientes "e na consciência como consciência intencionada ao mundo. Não pode ser a do depósito de conteúdos, mas a da problematização dos homens em suas relações com o mundo.
\end{abstract}

\title{
Considerações Finais
}

Diante do exposto nesse relato, acreditamos que o espaço escolar em interação com a universidade, via projetos como Pibid, pode ser um ambiente propício para contribuir positivamente na formação dos futuros professores, e também para avançarmos na busca por uma melhor qualidade de ensino na educação básica.

Essas contribuições se dão nas aprendizagens da docência que somente são construídas na relação com o outro, quando os licenciandos estão imersos no contexto escolar, vivenciando situações do cotidiano escolar. Essas aprendizagens poderão se constituir como saberes que farão parte da identidade dos futuros professores.

Entre as aprendizagens proporcionadas pelo subprojeto Química do Pibid da UFJF está a elaboração e aplicação de estudos de caso. Os bolsistas, em colaboração, tiveram que pesquisar, estudar e criar histórias que fossem significativas para os estudantes. Vale destacar que foi um desafio para muitos deles, já que o curso de Química não tem uma disciplina voltada ao estudo das doenças exploradas na atividade.

Além disso, ao dar voz aos alunos na roda de conversa e nas apresentações, os futuros educadores puderam identificar aspectos que despertariam o interesse das turmas para o estudo de ciências, além das dificuldades encontradas durante a resolução dos casos. 
Assim, diante dessas aprendizagens, percebemos que houve mudanças na postura dos bolsistas de iniciação à docência. Elas estão relacionadas a percepção da escola, enquanto ambiente de formação, além da universidade, e também em relação à carreira do magistério, que passou a ser vista com responsabilidade, dedicação e comprometimento.

\section{Agradecimentos}

A Capes pelo financiamento do subprojeto Química, integrante do Pibid da UFJF.

\section{Referências}

ALVARENGA, Mariana Monteiro Soares Crespo de Alvarenga; CARMO, Gerson Tavares; BRANCO, Amanda Leal Castelo. A utilização do método Estudo de caso sobre o Ensino de Ciências Naturais do Ensino Fundamental da Educação de Jovens e Adultos. Experiências em Ensino de Ciências, v. 13, n. 2, p. 126- 143, 2018.

BRASIL. Conselho Nacional de Educação. Diretrizes Curriculares Nacionais para os Cursos de Química. Brasília, 2001.

BRASIL. Coordenação de Aperfeiçoamento de Pessoal de Nível Superior. PIBID Programa Institucional de Bolsa de Iniciação à Docência. Brasília: 2020. Disponível em: https://capes.gov.br/educacao-basica/capespibid/pibid. Acesso em: 10 de ago. 2021.

ESTEVE, Francielle Escobar; COELHO, Franciele Braz de Oliveira. Abordagem da temática aproveitamento total dos alimentos no Ensino de Ciências da Natureza com enfoque interdisciplinar: relato de experiência no contexto da Educação Básica. Revista Insignare Scientia, v. 4, n. 4, p. 323-335, 2021.

FARIA, Edna Silva; FARIA, Viviane Fleury; SILVA, Célia Sebastiana. Contribuições do PIBID para a formação inicial docente: relato de experiências na UFG. Revista Ibero-Americana de Estudos em Educação, v. 16, n. esp. 1, p. 866-880, 2021.

FERNANDES, Carolina dos Santos; MARQUES, Carlos Alberto; DELIZOICOV, Demétrio. Contextualização na formação inicial de professores de Ciências e a perspectiva educacional de Paulo Freire. Revista Ensaio, v. 18, n. 2, p. 9-28, 2016.

FREIRE, Paulo. A Educação na cidade. São Paulo: Cortez, 1991.

FREIRE, Paulo. Pedagogia da autonomia: saberes necessários à prática educativa. 25. ed. Rio de Janeiro: Paz e Terra, 1996.

FREIRE, Paulo. Carta de Paulo Freire aos professores. Estudos Avançados, 15(42), p. 259268, 2001.

FEIRE, Paulo. Educação e mudanças. Rio de Janeiro: Paz e Terra, 2014.

FREIRE, Paulo. Educação como prática da liberdade. 49. ed. São Paulo: Paz e Terra, 2021.

JESUS, Maísa Pereira de; SILVA, Adjane da Costa Tourinho. A argumentação no ensino de CTS aliado à pedagogia de Paulo Freire. In: CONGRESO INTERNACIONAL SOBRE INVESTIGACIÓN EN DIDÁCTICA DE LAS CIENCIAS, 10, 2017. Disponível em https://ddd.uab.cat/pub/edlc/edlc_a2017nEXTRA/41_- 
A_argumentacao_no_ensino_de_CTS_aliado_a_pedagogia_de_Paulo_Freire.pdf Acesso em 14 ago. 2021.

LEE, Lundoi Tobias; FRANCISCO, Fernanda Rodrigues; FERREIRA, Carolina França; MEDEIROS, Thiago de Ávila. Abordagem da educação alimentar em livros didáticos de ciências do oitavo ano do Ensino Fundamental. Research, Society and Development, v. 10, n. 3, p. 1-9, 2021.

MENDES, Thamiris Christine; BACCON, Ana Lúcia Pereira. Profissão docente: o que é ser professor? In: CONGRESSO NACIONAL DE EDUCAÇÃO, 12, 2015. Curitiba. Anais [...]. Curitiba: Pontifícia Universidade Católica do Paraná, 2015, p. 39786-39803.

MIZUKAMI, Maria da Graça Nicoletti; REALI, Aline Maria de Medeiros Rodrigues; REYES, Cláudia Raimundo; MARTUCCI, Elisabeth Márcia; LIMA, Emília Freitas de; TANCREDI, Regina Maria Simões Puccinelli; MELLO, Roseli Rodrigues de. Escola e aprendizagem da docência: processos de investigação e formação. São Carlos: EdUFSCAR, 2006.

PANIAGO, Rosenilde Nogueira; SARMENTO, Teresa. A Formação na e para a Pesquisa no PIBID: possibilidades e fragilidades. Educação \& Realidade, v. 42, n. 2, p. 771-792, 2017.

ROSTAS, Marcia Helena Sauaia Guimarães. Formação de professores: aspectos de um processo em construção. Revista Internacional de Formação de Professores, v. 4, n.2, p. 169-185, abr./jun., 2019.

SÁ, Luciana Passos; QUEIROZ, Salete Linhares. Estudo de caso no ensino de química. São Paulo: Átomo, 2009.

SANT'ANNA, Paulo Afranio; MARQUES, Luiz Otávio Costa. Pibid Diversidade e a Formação de Educadores do Campo. Educação \& Realidade, v. 40, n. 3, p. 725-744, 2015.

SIQUEIRA, Douglas Eduardo Bueno de; SANTOS, Genivaldo de Souza. Alteridade e autoritarismo em Paulo Freire. In: SIMPÓSIO INTERNACIONAL DE EDUCAÇÃO E COMUNICAÇÃO, 10, 2021. Anais [...]. Sergipe: Universidade Tiradentes, 2021, p. 1-15.

SOUSA, Polliane Santos de; GEHLEN, Simoni Tormöhlen. Argumentação centrada em Questões Sociocientíficas e Educação Problematizadora: algumas relações. In:

ENCONTRO NACIONAL DE PESQUISA EM EDUCAÇÃO EM CIÊNCIAS, 10, 2015. Anais [...]. Águas de Lindóia: ABRAPEC, 2015, p.1-8.

TARDIF, Maurice. Saberes docentes e formação profissional. 17 ed. Petrópolis: Vozes, 2014.

WASUM, Karine da Silva; FRAGA, Jonas Grachten; MAURENTE, Viviane Maciel Machado. Paulo Freire em tempos de pandemia: refletindo sobre relações humanizadas no "novo" convívio escolar. In: MELO, Maria Aparecida Vieira de; TORRES, Maria Erivalda dos Santos; ALMEIDA, Ricardo dos Santos de (orgs.). Educação e prática pedagógica em Freire: desafios da atualidade. Recife: Centro Paulo Freire Estudos e Pesquisas, v. 1, 2021, p. 80102. 